\title{
Exploring the beliefs of native and non-native English speaking kindergarten teachers in Taiwan
}

Chang, Chiung Wen $\square$

R.O.C. Military Academy, Kaohsiung, Taiwan, R.O.C. (chiungwenchang@gmail.com)

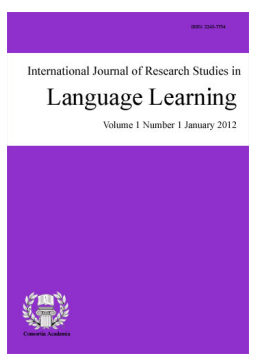

ISSN: 2243-7754 Online ISSN: 2243-7762

OPEN ACCESS

\section{Abstract}

This study investigates the beliefs of native and non-native English speaking teachers on teaching English in kindergartens. A qualitative case study design is used to construct individual portraits and a cross-case analysis of several kindergarten teachers and analyze data following the qualitative data analysis methods by Taylor and Bodgan (1998). Data collected by interview and classroom observation show 4 different beliefs to be salient across the cases: language learning, the role of the teacher, the role of the learner, and self-efficacy. Data analysis shows teacher beliefs that are complex and closely related to the teacher's life and learning experiences, multiple identities, and different environmental affordances and constraints. Therefore, the teachers' subjective account from an emic perspective is useful for describing this complexity. The findings of this study have implications for constructing "a technical culture" (Kleinsasser, 1993), in which teachers may find themselves, that supports the teacher, and that contributes to quality teaching and professional growth.

Keywords: teacher's belief; native-speaking English teachers (NESTs); non-native English speaking teachers (NNESTs); teaching English to young learners; English language teaching 


\section{Exploring the beliefs of native and non-native English speaking kindergarten teachers in Taiwan}

\section{Introduction}

The trend toward globalization and internationalization, in addition to the recognition of English as the international language of commerce, has caused numerous parents in Taiwan to make learning English as early as possible a matter of priority for their children. In response to this new global trend of early English language acquisition, the Ministry of Education (MOE) in Taiwan drafted a bill to the Legislature that was passed into law in 1997, which requires English to be taught as a compulsory subject in primary education curricula beginning in 2001, starting from Grade 5 through high school. In 2005, the MOE required that primary schools begin their English education from the third grade upward. Consequently, the age of English first-learners dropped from junior high school level to elementary, and in many cases down to preschool level. Numerous preschools claim to provide an English-only teaching environment, and English preschools and nursery schools (whether whole-day or half-day English teaching) seek aggressively for native English speakers to teach in their schools.

Although the EFL industry is flourishing in Taiwan (Yeh, 2002), government policy regulating the hiring of native-speaking English teachers (NSETs) is nonexistent. This situation has resulted in several problems. Many of these teachers are not fully qualified, which has a major negative influence on children's learning. The native-speaker fever is fueled by the belief that native speakers are perfect in their language. This might be true, but it is not so for every situation, particularly in English language teaching. This is because of the numerous types of challenges to overcome in the ELT classroom than simply measuring up to native-speaker status. Researchers have argued that the expertise of native speakers as teachers should be re-examined (Tajino \& Tajino, 2000; Auerbach, 2003; Medgyes, 1992; Rampton, 1990). Phillipson (1992) and Yang (2004) contended that a qualified language teacher is defined by his/her training and professional knowledge, not merely by his/her mother tongue. Despite the popularity of English immersion for preschoolers, certain scholars have expressed doubt on the suitability of native English speakers to teach Taiwanese children. This study therefore investigates the beliefs and practices of native and non-native English speaking teachers on teaching English in kindergartens in Taiwan.

This study yields preliminary information to assist those responsible for providing support to English teachers in preschools. This information allows them to better identify teacher needs, to provide appropriate in-service training and courses, and to improve the accreditation and guidance of kindergartens. The findings of this study have implications for constructing "a technical culture" (Kleinsasser, 1993) that supports the teacher, and contributes to quality teaching and professional growth.

\section{Literature review}

\subsection{Teacher Beliefs}

The past 20 years has generated growing interest in documenting teacher perceptions, understanding, and knowledge (e.g., Carter 1990; Clark \& Peterson 1986; Elbaz, 1991; Pajares, 1992). In the L2 teacher education field, Kleinsasser (1993, p. 372) called for the profession to "capture the essence and nuance of teachers' thoughts, beliefs, and actions in their workplace" (i.e., schools), particularly how teachers conduct their work in school contexts. Freeman and Richards (1996, p.1) commented "that in order to better understand language teaching, we need to know more about language teachers: what they do, how they think, what they know, and how they learn." Freeman and Johnson (1998, p. 402) argued "that the field must better document and understand teacher learning for teacher education to be more effective." They concluded that building sufficient 
knowledge includes language teaching and learning and the experience, knowledge, and beliefs of teachers as participants. In this investigation, knowledge is viewed as actively constructed by the person based on his or her personal experience and reason (e.g., Hoefer, 2000, 2004; Wood \& Kardash, 2002; Su, 2012). Beliefs and knowledge are used interchangeably in this study, considering the suggestion by Clandinin and Connelly (1987) that many of the personal knowledge constructs are simply different words that mean the same thing.

\subsection{English Class in preschool in Taiwan}

Under the pressure of parent expectation and the hardship of recruiting new students caused by the diminishing birth rate (Lin \& Sung, 2012), kindergartens are increasingly changing their curricula to cope with the tremendous demand for English teaching. The qualities and qualifications of kindergarten English teachers are questionable. No explicit standard exists for local English teachers; however, foreign English teaching violations are common in Taiwan, despite the proclamation of the Taiwanese Ministry of Education in 1981 that no foreigners are allowed to serve as English teachers in kindergartens. Ironically, illegal foreign teachers are currently easy to find in most kindergartens (Hsieh, 2010; Wu, 2004).

Not only is foreigner teaching forbidden, but the absence of Chinese or all English teaching is also not allowed in kindergartens (Supplementary Education Law, No.25, 2002; Kindergarten Education Law, No. 19, 1981). The Ministry of Education declared that the goals of kindergarten English teaching should be restrained to supplemental learning and understanding alien cultures, rather than developing excellence in English proficiency (Ministry of Education, 2004).

The only justification the Ministry of Education offers to forbid all-English preschool classes is that they interfere with the Chinese or Taiwanese enculturation of children. Officials fear that the outcome of such preschools would be the inability of children to grow up Chinese or Taiwanese. By becoming English-acculturated at a tender age, the fear is that children might become "bananas" - American-born Chinese who are yellow on the outside, but white on the inside. The fear, however, is groundless.

Teachers in Taiwan kindergartens consist of homeroom teachers, non-native, and native- speaking English teachers. Chang (2003) found that more than half of the kindergartens in Taiwan adopt the format of "one native-speaking English teacher and one homeroom teacher." The NEST is responsible for teaching English, whereas the homeroom teacher is typically an early childhood education major. In certain kindergartens, a non-native English- speaking teacher (non-NEST) may teach English, teach non-English classes, or work as a teaching assistant in English classes. S/he is also responsible for preparing the teaching materials, classroom management, and student counseling after classes. Although certain non-NESTs teach English and have a high workload, their salary is much less than their NEST colleagues (Yeh, 2002). Numerous parents believe that children can learn correct pronunciation from NESTs. Certain researchers, however, question the qualifications of NESTs and argue their superiority in early childhood education.

\subsection{Native and non-native English speaking teacher}

In his article "Native or non-native: who's worth more?" Medgyes (1992) addressed an intriguing and challenging issue. He argued that non-native speaking EFL teachers should have the same chance of becoming successful teachers as NESTs, despite their relative handicap in language competence. He suggested that non-NESTs could serve as imitable models of successful language learners, provide learners with more information on language learning strategies, anticipate more easily the difficulties learners might encounter, and be better able to assist them by sharing their mother tongue. Medgyes suggested that an ideal EFL environment maintains a balance between NESTs and non-NESTs, where they complement each other in their strengths and weaknesses.

Medgyes (1994) indicated that NESTs and non-NESTs are "two different species" (p.27) and proposed four hypotheses. NESTs and non-NESTs differ in their language proficiency, differ in their teaching behavior, their 
discrepancy in language proficiency accounts for most differences found in their teaching behavior, and they can be equally good teachers in their own right. Arva and Medgyes (2000) investigated the differences in teaching behaviors between NESTs and non-NESTs using 10 recorded lessons and interviews in a secondary school in Hungary. They found differences between NESTs and non-NESTs in target language proficiency and teaching style. The results of their study suggested a mismatch between stated policy and actual practice, and their classroom observations highlighted several issues the interviews ignored.

Benke and Medgyes (2006) examined learner perceptions in the differences between NESTs and non-NESTs. Their findings showed that these two teacher groups adopt distinctly different teaching attitudes and teaching methods. Compared with NESTs, non-NESTs have a more structured approach to teaching grammar and are good at addressing grammatical difficulties. Because of their familiarity with the local educational environment, they provide more exam preparation, supply the L1 equivalent of certain English words, and develop translation skills. However, the non-NESTs tend to use too much L1 in the classroom. Their poor pronunciation and outdated language are often criticized. However, NESTs are ideal models to imitate and are better able to elicit their learners to speak aloud. Learners stated that NESTs are friendlier, and that their lessons are lively and colorful. However, lower-level learners had difficulty understanding their NESTs. Without a shared L1, NESTs tend to leave problems unexplained. A communication gap between NESTs and their learners often occurs because of their different language and cultural backgrounds.

In addition to language proficiency, teaching attitudes, and teaching methods, error evaluation is another distinctive feature where NESTs and non-NESTs differ substantially. Non-NESTs are more severe in managing error problems. Hughes and Lascaratou (1982) stated that the judgment of a native speaker is whether the error impedes comprehension, whereas the non-native speaker judgment seems related to their ideas of what constitutes basic rules of the target language.

Numerous studies on native and non-native teachers have been conducted recently in Taiwan. A review of the studies conducted on NEST and non-NEST teaching practices indicates that these studies focused on a particular aspect of practice, that is, a teacher's speech and teacher-student interaction (Chen, 2004; Lin, 2004; Wu, 2004; Yeh, 2004). Studies conducting detailed analyses of NEST and non-NEST beliefs are scant. Most studies on the differences between NEST and non-NEST are based on self-reported data from teachers or student perceptions obtained through questionnaires. Arva and Medgyes (2000) indicated a gap between stated and actual behavior. Although several empirical studies have investigated teacher classroom lecturing, studies related to early childhood education are scant. None of the studies focused on the beliefs of NESTs or non-NESTs in kindergartens.

\section{Research design}

This study was designed as a modified multi-case study conducted over a short, intensive period to provide a cross-sectional look at four preschool English teachers and their classrooms in action. Case studies of these four preschool English teachers were constructed by closely examining each teacher and his or her classroom, comparing them, and providing examples of the teacher beliefs and classroom practices.

This study has two main purposes: (a) to provide a detailed description of how instruction in a preschool classroom is operationalized for each of these two English teachers. Previous studies have supported that interpretative observational research in this area provides insight into how teachers conduct their classroom practices (LeCompte \& Preissle, 1993; Dufon, 2002); and (b) to record the thinking of these four English teachers on learning and teaching, to determine what beliefs are different between NESTs and non-NESTs. Determining their beliefs is important because they are often responsible for initiating change, implementing various practices, and creating an integrated curriculum. However, neither native nor non-native English speaking kindergarten teachers have apparently ever participated in such studies. To understand how English teaching operates in kindergartens requires learning more about the type of thinking and decision making of 
teachers in preschool settings. Understanding teacher beliefs contributes to an understanding of how to refine and improve teaching in a school setting (Kleinsasser, 1993).

In this study, we investigate these issues using the following framework and research question. Isenberg (1990) suggested that researchers document teacher thoughts before, during, and after the act of teaching, using a stimulated recall procedure. Such studies record and organize established standards of practices for particular teaching areas, in this case, kindergarten English teaching (Isenberg, 1990). In this paper, we apply this general framework to conduct a qualitative study, and combine the use of interviews and observations to discover and examine the beliefs and practices of four kindergarten English teachers to answer the following question: What are the beliefs of native and non-native English- speaking teachers concerning teaching English in kindergartens?

\subsection{Settings}

This study was undertaken in four preschools: three located in Kaohsiung, and one in Pingtung. These four kindergartens were appropriate for our research aims because they are closely related to the research interest and are a rich information source. Second, the time allotted to English teaching at these preschools is considered average. The subjects and the amount of instruction are nearly identical for the four campuses. A typical week for a student at one of these schools includes academic hours necessary for kindergartens by the Taiwanese MOE, in areas such as language arts, mathematics, science, social studies, arts and crafts, music and movement, and physical education. These schools represent preschool populations in Taiwan for English teaching. The information on the four kindergartens is summarized in Table 1.

\section{Table 1}

Information of Research Sites

\begin{tabular}{lccl}
\hline \multicolumn{1}{c}{$\begin{array}{c}\text { Name } \\
\text { Pseudonym) }\end{array}$} & Locations & Numbers of pupils & \multicolumn{1}{c}{ English Instruction } \\
\hline Riverside & Kaohsiung & 300 & Native \& Non-native Speakers of English \\
Forest & Pingtung & 80 & Native \& Non-native Speakers of English \\
Mountain & Kaohsiung & 200 & Non-native Speakers of English \\
Experimental & Kaohsiung & 120 & Native Speakers of English \\
\hline
\end{tabular}

\subsection{Participants}

The 4 participants were selected based on opportunity and convenience. Patton (1990) called this a purposeful sample. The demographics of these 4 participants are summarized in Table 2. The participants were informed that the purpose of this study was to investigate the beliefs of NESTs and non-NESTs, and that strict anonymity and confidentiality would be guaranteed.

Table 2

Participant Background

\begin{tabular}{|c|c|c|c|c|c|c|c|}
\hline $\begin{array}{c}\text { Name } \\
\text { (Pseudonym/ } \\
\text { Abbreviation in } \\
\text { interview } \\
\text { excerpts) }\end{array}$ & Sex & Age & Educ. & $\begin{array}{c}\text { Years } \\
\text { of } \\
\text { teaching } \\
\text { English }\end{array}$ & $\begin{array}{c}\text { Years of } \\
\text { Teaching } \\
\text { English at } \\
\text { Preschools }\end{array}$ & Country of origin & $\begin{array}{c}\text { Campus of current } \\
\text { teaching }\end{array}$ \\
\hline Michael (T1) & $\mathrm{M}$ & 39 & BA & 4 & 3 & South Africa & Riverside \\
\hline Ivy (T2) & $\mathrm{F}$ & 36 & BA & 8 & 5 & Taiwan & Forest \\
\hline Josh (T3) & M & 24 & BA & 1.5 & 1.5 & Canada & Experimental \\
\hline Irene (T4) & $\mathrm{F}$ & 30 & BA & 6 & 6 & Taiwan & Mountain \\
\hline
\end{tabular}




\subsection{Data collection}

Qualitative research procedures (Bogdan \& Bilken, 1998) were used in both the data collection and data analysis. The case study approach was chosen because neither language learning nor teaching experience of the study population is "readily distinguishable from its context" (Yin, 1993, p. 3). Data were collected at the four kindergartens by the following means:

$>$ A series of tape-recorded classroom observations of lessons conducted by the four teachers was conducted. Each lesson was approximately $40 \mathrm{~min}$.

$>\quad$ A descriptive account of the classroom observation for each lesson was then documented. From this account, the author conducted a preliminary analysis of the lesson structure to identify emerging interaction patterns and classroom task and activity sequences. These were compared and matched to teacher responses. A comparison was also made across the four teachers.

$>$ Four semi-structured interviews of appropriately 60 min were held with each teacher at the beginning and end of the classroom observations. All interviews were audio-recorded, with participant permission.

\section{Result and discussion}

In this study, the data for analysis include the interview transcriptions with the teachers and the recorded classroom observations. These were analyzed following the data analysis methods in qualitative research as suggested by Taylor and Bodgan (1998). They maintained three distinct activities involved in qualitative data analysis, namely, discovering, coding, and discounting data.

Data presented in this study were primarily derived from the teachers as main participants, to understand their beliefs and practices toward English teaching. The author decided to allow the data to speak for themselves, through the voices of teachers. The data are in the form of quotes, with the language used by the teachers retained in its original form. The designated data (participating teacher, date of the data collected, type of transcript) refer to relevant information concerning the data. For example (T1, 150107, interview transcript) represents an excerpt from the interview with T1 on January 15, 2007.

\subsection{Language Learning}

Michael expressed himself in favour of the view that learning a second/foreign language is the same as mother tongue acquisition, that is, it can be acquired naturally through direct exposure and contact with native speakers of the target language. Evidence of this belief exists in the following excerpt:

...they missed a great opportunity, because they have a full semester with a native speaker. All they have to do is sit and listen and pay attention. That's more important than anything else they think they have to do... If you don't understand, just listen harder and pay attention because your mind is working all the time (T1, 150107, interview).

Michael believed that when students notice the gap between their own language and that of native speakers, improvements and learning occur.

Explicit attention to grammar rules was not part of the literacy practice in Michael's classroom. Instead, grammatical errors were corrected indirectly through suggestion, emphasizing experimentation and allowing the children to make mistakes as part of the learning process. A grammatical incident occurred only when there were interactions between him and the children during storytelling time. Michael never selected different grammar points from the storybooks and talked about them. The following is an illustrative quote from the classroom observation note: 
Michael finished the last sentence in the book:

"Oops- one other thing is true: Your monster mama loves you too."

Tony: "So scary."

Michael: "You think this monster is scary?"

Tony explained: "This monster more strong than that one."

Michael corrected his grammar: "Is stronger, more stronger, or stronger?"

(Tony approached the front of the room and pointed at the monster in the book he was referring to while correcting his own grammar.)

Tony: "This monster is stronger than that one."

Michael never said directly that Tony was wrong. He simply asked Tony to make a choice. Tony quickly understood what Michael was referring to, and when he repeated the sentence, he was able to correct himself. Although Michael did not focus on grammar in his class, rules occasionally surfaced during conversations, similar to children learning their mother tongue. Michael often corrected in a subtle way by saying it again correctly rather than confronting the students with the mistakes they made.

Unlike Michael, Ivy believed that the younger the student, the better s/he was in learning the language. In support of the early age argument, the following anecdotal evidence was related:

It probably depends on the age of the learners. Certainly, young learners are going to be able to pick up the language and adults have more difficulty in becoming native speakers unless they work hard. You must accept that (T2, 160107, interview).

Regarding language learning, Ivy seemed to take a younger-is-better position and believed that the earlier children begin to learn a second language, the better. However, in a school setting, the literature does not support this view (e.g., Nikolov, 2000). Pronunciation is one aspect of language learning where the younger-is-better hypothesis may have validity. Aside from the question of pronunciation, however, the younger-is-better hypothesis does not have strong empirical support in school contexts. Studies suggest that younger children do not necessarily have an advantage over older children and, because of their cognitive and experiential limitations when compared to older children, all things being equal, they are actually at a disadvantage in how quickly they learn a second language.

When I asked the teachers how students learn English optimally, both Irene and Josh spoke about the importance of student interest. These teachers seemed to view student interest in English as a prerequisite to learning. For example, Josh explained student learning in the following manner:

First, they need to have interest. With the premise of being interested...they can grasp the knowledge in the class (T3, 180107, interview).

Both Josh and Ivy mentioned student interest as their primary responsibility as a teacher to develop in their students toward learning English. They stated or strongly implied that they held themselves accountable for their students' interest in English. For example, Irene mentioned this responsibility when she was asked how students learn English optimally:

First, he should love English. He cannot say, "I don't like English." That won't work, so the teacher must get him to love it (T4 020307, interview).

In summary, Josh and Ivy mentioned the importance of developing student interest and believed they were responsible for developing their students' interest in English. 


\subsection{Teacher and Learner Roles}

Michael believed that the teacher should be a facilitator. A teacher should give students opportunities to learn in as many different ways as possible. He said the following:

The most important role for me is to make sure that their learning occurs and to facilitate their moving on to the next stage of learning and not spoil their motivation, but facilitate it (T1, 120207, interview).

Michael expected learners to take an active role in language learning. He believed that teacher and learner roles were complementary, and that the ideal relationship is one in which teacher and learners work together. The following quote highlights these aspects:

Learners must understand that what teachers can do is limited, and that learners must do a lot on their own. The learner role involves going to classes, being active in the classroom, and not taking the teacher's word as absolute (T1, 120207, interview).

Ivy's beliefs on teacher and learner roles differed from those of Michael. Ivy believed that a good teacher makes effort to pass content to students and to establish good didactics. Ivy mentioned the following:

I had a very good teacher. You knew that that class had been well prepared. She prepared the class for us. At the end of the class, she talked to you about your difficulties. The next day she would bring something for you and say, "Look, I think that the grammar of the book is not enough. I brought another that I think is better about this aspect." Thus, I think what she did motivated me to learn (T2, 100207, interview).

Ivy believed that students had to be available, that is, obey and focus on the teacher. The following is a revealing quote:

I think a good student is one who is available to learn, s/he must make an effort to follow what is being given, s/he must do the exercises. There is no way English is going to get into your head. You have to do the exercise. I think there is this collaboration. To be open, available, make a personal effort (T2, 100207, interview).

Josh believes that the teacher's role is to make language available to students so that both students and teachers can construct meaning. In this process, the teacher is a mediator and a co-participant and the learner is not a passive recipient of knowledge but a constructor of language. He expressed that all children learn differently, and that one must occasionally continue to attempt different methods until a teacher finds what works for each child.

A teacher must adjust her teaching to accommodate that child. We can't expect them all to learn the same way. Similar to building something, teaching is like helping students to build something for themselves, like an engineer (T3, 200108, interview).

Irene believes that the teacher's role is to nourish, influence, and foster the potential capacities of the learner. She attempts to provide emotional support when it is required and help learners feel secure and confident about language learning. She stated the following:

I feel I have to be very patient, so I feel like a counselor; no matter what students say (good or bad), you must listen even you are very tired (T4,150407, interview ).

Another aspect of effective teaching, as expressed by Irene, was that of using real-life experiences to enhance and guide lessons. Irene spoke at length about the importance of using what students brought with them to make classroom experiences more relevant and meaningful. In her view, this did not minimize the importance 
of having a lesson plan and knowing the content and state standards. However, these often served as the backbone for a lesson that occasionally changed form because of what children brought up in class or wrote in their notebooks. "You have to be able to listen and say, "How can I turn that into a major, dynamite lesson?", Irene characterized her teaching as "off the cuff," although this meant she was flexible and responsive, rather than unprepared.

\subsection{Self-efficacy}

The analysis of the interviews helped identify one source of strength for the NNESTs: linguistic advantage provided by the non-native status. The interviewees explained that the feature that characterized NNESTs was linguistic advantage. The NESTs agreed that the NNESTs' ability to communicate with their students' parents promoted positive parent-teacher rapport. The NESTs also explained that students typically see their NNESTs as role models with whom they can identify and relate. The following comments reflect on this issue:

They provide a communication link to some students, similar to an interpreter (T4, 170507, interview).

They have good communication skills with parents and help them to understand how the school operates and how they can assist their children in English learning to become successful learners (T1, 080607, interview).

Non-native speaker teachers are more likely to understand the needs and obstacles of foreign/second language learners. The NNEST is able to predict possible situations that might occur in the classroom. Growing up in the same background culture is a benefit to the NNEST because they can explain certain ideas more precisely by comparing those to similar existing concepts in their native language/culture. This comparison smooths student anxiety in learning a new language (T4, 230507, interview).

During the interviews, two NNESTs were more positive about their instructional abilities than were the NESTs. The NESTs were perceived to be less professional by the two NNESTs, who believed their counterparts to be unprepared for their classes. The ability of NNESTS to communicate with their students' parents may have contributed to the NNESTs' positive perceptions on their instructional abilities. The statements of the participating teachers seemed in line with the result obtained by Phillipson (1996).

When participating teachers were asked, "How would you describe the most important contributions of native-speaker teachers to L2 learning/ teaching?" they answered as follows:

Instructed by foreign teachers, preschool pupils are given a good start to develop correct pronunciation by being exposed to native English speakers (T4, 180907, interview).

The opportunity to be with native speakers of the target language at a young age helps reduce student fear of speaking English to foreigners (T1, 260607, interview).

Foreign teachers can simultaneously introduce Western culture and customs, thus providing students with a broader world perspective (T2, 140307, interview).

Whereas participating teachers responded to the question, certain ones also indicated the following NEST limitations: 
According to the cognitive development of children, a great sense of teacher anxiety and uncertainty may cause children to become confused in learning English without an explanation in their familiar language (T2, 250407, interview).

Although NESTs are fluent in English, they do not necessarily possess knowledge of the complexity of English grammar (T4, 180108, interview).

NESTs have additional communication and coordination problems related to administrative work and classroom teaching (T1, 290307, interview).

As reported in this study, NEST participants expressed a high level of anxiety and discomfort when teaching English to preschool learners. They attributed these feelings to their lack of ability to communicate with the learners and parents. The ideology of the native English speaker as the ideal teacher, readily adopted by the Taiwan people, does not grant native English teachers legitimacy as teachers in their everyday interactions with Taiwanese teachers of English and Taiwanese students.

The data analysis showed that teacher beliefs on language teaching represented their experiential reasoning and were related to their immediate context - the language classroom-and to their multiple identities as teachers, learners, and members of a certain culture of learning and teaching languages (Johnson, 2006; Liu, 1999). Teacher beliefs are complex and closely related to teacher life and learning experience, multiple identities, and different environmental constraints. The teachers' subjective account from an emic perspective is useful in disclosing this complexity.

Despite all the challenges NNESTs face, the literature reports that they bring numerous positive attributes to the classroom to enhance learning (Medgyes, 1994; Phillipson, 1992). The NNEST participants in this study stated several of their attributes, including sharing the same language with students, having been through the complex process of learning English, awareness of difficulties students encounter, and empathizing with them.

In conclusion, as Medgyes (1992) indicated, NESTs and NNESTs differ significantly in their teaching practice resulting from their divergent language background; however, teacher effectiveness does not depend on being a native English speaker. This study demonstrates that the dichotomy of the native speaker of English as a superior teacher, and the non-native speaker of English as an inferior teacher, is too simplistic to explain real-life experiences of NESTs.

\section{Conclusion and implications}

The data analysis shows that teacher beliefs are complex, closely related to their life and learning experiences, their multiple identities, and different environmental affordances and constraints. The subjective account of teachers from an emic perspective is useful in disclosing this complexity.

The findings in this study make a few implications for language teaching education programs.

$>\quad$ The Taiwanese government should make laws governing kindergarten English classes, so that all public and private kindergartens can legally offer English classes. Rather than prohibiting the teaching of English in kindergartens, educational authorities should explore avenues for increasing exposure to language and minimize any negative effects that such exposure might have on the learning of native language and culture by children.

$>\quad$ In developing an appropriate pedagogy, local educators should consider how English is embedded in the local context. According to Kramsch and Sullivan (1996), an appropriate pedagogy for teaching EIL depends on local ELT professionals thinking globally, but acting locally_possessing global 
Exploring the beliefs of native and non-native English speaking kindergarten teachers in Taiwan

awareness coupled with local knowledge. It is unrealistic to acquire all the knowledge and skills separately without considering the integrity of the pedagogical setting as a whole (Okazaki, 2000).

D The government should consider how to train all English teachers and how to ensure job security for foreign English teachers, to motivate them to teach long term in kindergartens. The government must establish laws to allow foreign English teachers to teach legally in kindergartens and to encourage them to remain in kindergartens longer. The Educational Bureau could also invite NESTs to conduct meetings and to submit their suggestions and problems they encounter, to enlist the help of government.

D Discussing native versus non-native speakers as teachers overlooks certain important issues. Teacher language proficiency is only one element of professionalism. Another concern is whether the person is appropriately prepared to be a teacher. We must look beyond the labels and see teachers as individuals, with particular strengths and areas for improvement.

$>$ Both local Taiwanese teachers of English and native-speaking foreign teachers need to understand each other's customs, behaviors, and personality types, so that all teachers can develop proper awareness toward working together professionally and harmoniously, to help their students reach higher levels of "immersion."

D Early childhood educators face tremendous challenges in supporting children's language development. Because children acquire language best in meaningful contexts, through conversational interactions, and through encounters with written language, these must be the focus of instruction for teacher candidates.

With the light shed by the results from the present study, the author wishes to make some suggestions for language learners and language teachers:

D Admittedly, NESTs are recognized as assets to English learning, but they are also advised to adjust to the changing teaching/learning environment. Language learning and teaching are closely related for both teachers and students. Learning and teaching a foreign language, for both teachers and students, implies a degree of intercultural learning. Possessing this attitude will facilitate both foreign teachers and local students to increase the learning and teaching efficiency. Thus, how to improve teachers' personal weakness and take advantage of their own strengths is one of the crucial issues for any teachers of different culture

$>\quad$ New NESTs might carry certain stereotypes about Taiwanese students, such as being obedient and lacking opinions, and these misconceptions also need to be clarified as well. The educational and societal environment in Taiwan has gone through drastic transformations in the past two decades; as a result, students may grow up in very different contexts. While more cultural understanding from NESTs would definitely benefit teaching and learning, treating each student as a special human being is a must for every teacher.

> Many EFL students have little experience interacting with foreigners. Thus, a lot of the misconceptions students have come from biased messages in the media and traditional rhetoric about foreigners. However, the environment has changed, and more students are getting into contact with foreigners. If offered the opportunity, these students can provide first-hand experience and fairer impressions for others who still hold to the old stereotype. While some clarification from teachers helps, the testimony from their peers is more powerful and effective. If the school is able to include in its orientation a discussion of this issue, such gap in understanding would be greatly bridged. Seeing each teacher as a unique individual and accepting all other traits of the teacher-- such as race, gender, and language without forming predetermining perception from these traits-- is the underlying norm 
that the orientation intends to help students adopt.

$>\quad$ Both NESTs and NNESTs are suggested to rethink their roles and adjust self-expectation as the world changes rapidly. It would be not only proper but beneficial to language teaching to accept the existence of "the glaring differences between natives and non-natives" (Medgyes, 1992, p343)

This study was conducted on a small scale, with only four teachers. In light of the dearth of research on teacher beliefs and practice related to teachers in kindergarten English classes, and because of the ever-increasing diversity of English teacher populations, conducting further research of a similar nature is critical. A larger sample size, and one that represents a cross-section of areas of Taiwan or EFL countries, could yield results that would further inform the education community. Longitudinal studies on kindergarten English teachers could provide insight into how beliefs are shaped across time and experiences.

\section{References}

Arva, V., \& Medgyes, P. (2000). Native and non-native teachers in the classroom. System, 28, 355-372. http://dx.doi.org/10.1016/S0346-251X(00)00017-8

Auerbach, E. (1993). Reexamining English only in the ESL classroom. TESOL Quarterly, 27(1), 9-31. http://dx.doi.org/10.2307/3586949

Benke, E., \& Medgyes, P. (2006). Differences in teaching behavior between native and non-native speaker teachers: As seen by learners. In E. Llurda (Ed.), Non-Native language teachers: Perceptions, challenges and contributions to the profession (pp.195-216). New York: Springer.

Bogdan, R. C., \& Biklen, S. K. (1998). Qualitative research for education: An introduction to theory and methods. Needham Heights, MA: Ally \& Bacon.

Carter, K. (1990). Teachers' knowledge and learning to teach. In W. R. Houston (Ed.), Handbook of research on teacher education (pp. 291-310). New York: Macmillan.

Chang, H. L. (2003). A study of English learning condition of young kids: An example of an English only kindergarten in Taichung city. Unpublished master's thesis, Nanhua University, Chiayi, Taiwan.

Clark, C. M., \& Peterson, P. L. (1986). Teachers' thought processes. In M.W. Wittock (Ed.), Handbook of Research on Teaching (pp.255-296). New York: Macmillan.

Connelly, F. M., \& Clandinin, J. (1986). On narrative methods, personal philosophy, and narrative unities in the study of teaching. Journal of Research in Science Teaching, 23, 293-310. http://dx.doi.org/10.1002/tea.3660230404

Dufon, M. A. (2002). Video recording in ethnographic SAL research: Some issues of validity in data collection. Language Learning \& Technology, 6(1), 40-59.

Elbaz, F. (1991). Research on teachers' knowledge: The evolution of a discourse. Journal of Curriculum Studies, 23, 1-19. http://dx.doi.org/10.1080/0022027910230101

Freeman, D., \& Johnson, K. E. (1998). Reconceptualizing the knowledge base of language teacher education. TESOL Quarterly, 32(3), 397-417. http://dx.doi.org/10.2307/3588114

Freeman, D., \& Richards, J. C. (1996). Prologue: A look at uncritical stories. In D. Freeman and J.C. Richards (Eds.) Teacher learning in language teaching (pp.1-6). Cambridge: Cambridge University Press.

Hoefer, B. K. (2000). Dimensionality and disciplinary differences in personal epistemology. Contemporary Educational Psychology, 25, 378-405 http://dx.doi.org/10.1006/ceps.1999.1026

Hoefer, B. K. (2004). Exploring the dimensions of personal epistemology in different classroom contexts: Student interpretations during the first year of college. Contemporary Educational Psychology, 29,129-163. http://dx.doi.org/10.1016/j.cedpsych.2004.01.002

Howes, C,. \& Ritchie, S. (2002). A matter of trust. New York: Teachers College Press.

Hsieh, M. F. (2010). Teaching young children English: Experiences of native and nonnative English speaking teachers. English Teaching and Learning, 34(2), 45-98.

Isenberg, J. P. (1990). Teachers' thinking and beliefs and classroom practices. Childhood Education, 66, $322-327$. http://dx.doi.org/10.1080/00094056.1990.10522549 
Exploring the beliefs of native and non-native English speaking kindergarten teachers in Taiwan

Johnson, K. E. (2006). The sociocultural turn and its challenges for second language teacher education. TESOL Quarterly, 40(1), 235-257. http://dx.doi.org/10.2307/40264518

Kleinsasser, R. C. (1993). A tale of two technical cultures: Foreign language teaching. Teaching and Teacher Education, 9(4), 373-383. http://dx.doi.org/10.1016/0742-051X(93)90004-Z

Kramsch, C., \& Sullivan. P. (1996). Appropriate pedagogy. ELT Journal, 50(3), 199-212. http://dx.doi.org/10.1093/elt/50.3.199

LeCompte, M. D., \& Preissle, J. (1993). Ethnography and qualitative design in educational research. San Diego: San Diego Academic Press.

Lin, H. F. \& Sung, H.C. (2012). A comparative study on the Kindergarten evaluation system between Taiwan and Hong Kong. International Journal of Research Studies in Education, 1(2), 23-30. http://dx.doi.org/10.5861/ijrse.2012.v1i2.54

Lin, H. Y. (2004). Teacher talk of native and non-native English teachers in EFL classrooms. Unpublished master's thesis, Ming Chuan University, Taipei, Taiwan.

Liu, J. (1999). Nonnative-English speaking professionals in TESOL. TESOL Quarterly, 33(1), 85-102. http://dx.doi.org/10.2307/3588192

Medgyes, P. (1992). Native or non-native: who's worth more? ELT ournal,46(4), 340-349.

Medgyes, P. (1994). The non-native teacher. London: Macmillan Publishers.

Nikolov, M. (2000). The Critical Period Hypothesis reconsidered: Successful adult learners of Hungarian and English. IRAL, 38(2), 109-124. http://dx.doi.org/10.1515/iral.2000.38.2.109

Okazaki, H. (2010). Language teacher's training based on reflection model: What can be provided for trainees, Language Culture: Japanese Language Education, 20, 1-12

Pajares, M. F. (1992). Teacher's beliefs and educational research: Cleaning up a messy construct. Review of Educational Research, 62(3), 307-332.

Patton, M. (1990). Qualitative Evaluation and Research Methods. Newbury Park, CA: Sage Publications.

Phillipson, R. (1992). Linguistic imperialism. Oxford: Oxford University Press.

Phillipson, R. (1996). ELT: The native speaker's burden. In T. Hedge \& N. Whitney (Eds.), Power, Pedagogy \& Practice (pp. 23-30). Oxford: Oxford University Press.

Pianta, R. C. (1999). Enhancing relationships between children and teachers. Washington, DC: American Psychological Association. http://dx.doi.org/10.1037/10314-000

Rampton, M.B.H. (1990). Displacing the "native speaker": Expertise, affiliation, and inheritance. English Language Teaching Journal, 44, 97-101. http://dx.doi.org/10.1093/elt/44.2.97

$\mathrm{Su}$, Y. N. (2012). Teach to live or live to teach: A case study on the educational beliefs of displaced teachers in Taiwan. International Journal of Research Studies in Education, 1(1), 3-20. http://dx.doi.org/10.5861/ijrse.2012.v1i1.2

Tajino, A., \& Tajino, Y. (2000). Native and non-native: What can they offer? ELT Journal, 54(1), 3-11. http://dx.doi.org/10.1093/elt/54.1.3

Taylor, S. J., \& Bogdan, R. (1998). Introduction to qualitative research methods ( $3^{\text {rd }}$ ed.). New York: John Wiley.

Wood, P., \& Kardash, C. (2002). Critical elements in the design and analysis of studies of epistemology. In B. K. Hoefer and P.R. Pintrich (Eds.) Personal epistemology: The Psychology of beliefs about knowledge and knowing (pp. 231-260). Mahwah, NJ: Erlbaum.

Wu, Y. L. (2004). The case study of teacher-pupil interaction in the kindergarten English classroom. Unpublished Ph.D. dissertation, National Kaohsiung Normal University, Kaohsiung, Taiwan.

Yang, N. D. (2004, November, 12-14). Autonomous learning and Web-based English learning. Paper presented at the Thirteenth International Symposium and Book Fair on English Teaching, Taipei, Taiwan, R.O.C.

Yeh, A. (2002). Teaching English in Taiwan: Issues of inequality and low motivation. English Today, 18(4), 50-52. http://dx.doi.org/10.1017/S026607840200408X

Yeh, Y. F. (2004). Teacher-pupil talk and interaction in a bilingual kindergarten English class. Unpublished master's thesis, National Taipei Teachers College, Taipei, Taiwan.

Yin, R. (1993). Applications of case study research. Newbury Park, CA: Sage Publishing. 
Chang, C. W. 